\title{
Mineral Slag used as an Alternative of Cement in Concrete
}

\author{
Eskinder Desta Shumuye ${ }^{1 *}$, Jun Zhao ${ }^{2}$, Zike Wang ${ }^{3}$ \\ ${ }^{1 *, 2}$ School of Civil Engineering, Zhengzhou University \\ Zhengzhou 450001, China. \\ ${ }^{3}$ School of Mechanics and Safety Engineering, Zhengzhou University \\ Zhengzhou 450001, China. \\ 1*eskdes@gmail.com
}

\begin{abstract}
This paper summarizes the results of experimental studies carried out at Zhengzhou University, school of Mechanics and Engineering Science, research laboratory, on the performance of concrete produced by combining ordinary Portland cement (OPC) with ground-granulated blast furnace slag (GGBS). Concrete specimens cast with OPC and various percentage of GGBS $(0 \%, 30 \%, 50 \%$, and $70 \%)$ were subjected to high temperature exposure and extensive experimental test reproducing basic freeze-thaw cycle and a chloride-ion attack to determine their combined effects within the concrete samples. From the experimental studies comparisons were made on the physical, mechanical, and microstructural properties in compassion with ordinary Portland cement concrete (OPC). Further, durability of GGBS cement concrete such as exposure to chloride ion attack and freeze-thaw action in compassion with various percentage of GGBS and ordinary Portland cement concrete of similar mixture composition were analyzed. The microstructure, mineralogical composition, and pore size distribution of concrete specimens were determined via Scanning electron microscopy analysis (SEM), and $\mathrm{X}$-ray diffraction (XRD). The result demonstrated that when the exposure temperature increases from $200{ }^{\circ} \mathrm{C}$ to $400{ }^{\circ} \mathrm{C}$, the residual compressive strength was fluctuating for all concrete group; and compressive strength and chloride ion exposure of the concrete decreased with the increasing of slag content. The SEM and EDS results showed an increase in carbonation rate with increasing of slag content.
\end{abstract}

Keywords: Concrete, GGBS, Crack, Chloride ion, Carbonation, High temperature

\section{Introduction}

With the increasing awareness of $\mathrm{CO}_{2}$ emission reduction in all construction sectors, mineral cementitious materials has been regarded as a prominent alternative to ordinary Portland cement (OPC) [1]. Supplementary cementitious materials (SCM) such as, ground granulated blast furnace slag (GGBS), fly ash (FA), metakaolin are the emerging products that can replace OPC to minimize emission of greenhouse gases in the environment which leads to global warming [2]. Fly ash can replace up to $50 \%$ of OPC in concrete mixture, and the $25 \%$ replacement of fly ash is common. GGBS as well commonly replaces up to $40 \%$, and can be also replaced up $80 \%$ [3], [4].

The chemical composition of mineral slag varies noticeably depending on the chemical composition of the raw materials in the production process. The main constitutes of the slag are lime, silica and alumina similar as that of OPC and is collected from iron or steel processing industry [2], [5]. GGBS is less in lime content than OPC, the availability of alumina in GGBS is higher than OPC. Depends on the amount of GGBS concrete fabricated from GGBS sets more slowly and gain strength over time. This results in low temperature rise and heat of hydration [5].

Calcium silicate hydrate gel $(\mathrm{C}-\mathrm{S}-\mathrm{H})$, Calcium hydroxide $\left[\mathrm{Ca}(\mathrm{OH})_{2}\right]$ and Calcium sulfoaluminate $\left[\mathrm{Ca}_{6} \mathrm{Al}_{2}\left(\mathrm{SO}_{4}\right)_{3}(\mathrm{OH})_{12} \cdot 26 \mathrm{H}_{2} \mathrm{O}\right.$ ] produces during the hydration of Portland cement [6]. The production of Calcium hydroxide during the hydration produces greatly affect the quality of concrete as it is partly soluble in water and decrease in strength [5]. GGBS has explicit effect on hydration activities and pozzolanic activities, which $\mathrm{Ca}$ $(\mathrm{OH})_{2}$ is consumed, and additional C-S-H gels is produced during the hydration process. Therefore, this leads to a denser microstructure and higher compressive strength as well as better concrete durability at later age [5], [6].

Despite of significant achievement made in construction technology in recent years, the problem of unsatisfactory durability of concrete structure are still the major concern in the international community of 
engineer's todays [7]. During the application of new building materials into practice, they should have a required degree of fire and corrosion resistance. The basic deterioration phenomena of reinforced concrete are such as fire exposure, carbonation and chloride ion penetration. When a concrete building is subjected to fire disaster, the ultimate strength and its physical properties of the concrete structure may be critically affected after fire exposure [8]. Corrosion of steel reinforcement is the most concerning problem of reinforced concrete durability. The effect of corrosion not only affect the appearance of the structure, but also its strength and safety, due to the reduction in cross-sectional area of reinforcement and the reduction of bond strength of the concrete [7]. The carbonation of concrete is also a well-known process. The diffusion of $\mathrm{CO}_{2}$ into the concrete structure, results change in the phase of the hydrated binder such as, $\mathrm{CaO}, \mathrm{SiO}_{2}, \mathrm{Aft}, \mathrm{Afm}$ and $\mathrm{C}-\mathrm{S}-\mathrm{H}$. Carbonation reaction leads to a decrease in $\mathrm{pH}$ and result in changing the microstructure of concrete structure. It is known that the decrease in $\mathrm{pH}$ increase the risk of corrosion. Thus, determining the rate of carbonation rate is necessary to predict the durability of reinforced concrete structures.

In this research, concrete specimens cast with OPC and various percentage of GGBS $(0 \%, 30 \%, 50 \%$, and $70 \%$ ) were fabricated and tested to extensive experimental tests reproducing high temperature exposure, accelerated carbonation, basic freeze-thaw cycles and a chloride-ion attack to determine their combined effect on concrete properties.

The experimental data presented in this paper may assist in the application of mineral slag to the sustainable development of construction industry and helps building materials manufacturer to understand the comprehension of mineral slag behavior.

\section{Experimental program}

\subsection{Materials}

The materials used in this experimental test were comprised of ground-granulated blast furnace slag (GGBS), ordinary Portland cement (OPC), sand, crushed granite and water. A standard ordinary Portland cement (OPC) (PO 42.5 R) and adhering to the ASTM International standard specification C989-09[9] and a grade S-95 slag cement were chosen for this experimental test adapted to Chinese standard specification GB175 and GB/T18046[10]. The locally available river sand with a fineness modulus of 2.69 and a crushed granite coarse aggregate with a minimum size of $4.75 \mathrm{~mm}$ and maximum size of $10 \mathrm{~mm}$ and $19 \mathrm{~mm}$ were also used. The chemical composition of the ground-granulated blast furnace slag (GGBS) and ordinary Portland cement (OPC) were characterized by X-ray fluorescence (XRF) and are presented in Table 1.

Table 1: Chemical compositions and specific gravities of ordinary Portland cement and ground-granulated blast-

\begin{tabular}{l|l|l}
\multicolumn{2}{c}{ furnace slag (GGBS) (wt.\%) } \\
\hline Component (\%) & Cement & GGBS \\
\hline $\mathbf{S i O}_{\mathbf{2}}$ & 17.945 & 26.713 \\
\hline $\mathbf{A l}_{\mathbf{2}} \mathbf{O}_{\mathbf{3}}$ & 4.465 & 14.748 \\
\hline $\mathbf{F e}_{\mathbf{2}} \mathbf{O}_{\mathbf{3}}$ & 3.558 & 0.472 \\
\hline $\mathbf{C a O}$ & 64.562 & 43.093 \\
\hline $\mathbf{M g O}$ & 3.751 & 10.145 \\
\hline $\mathbf{R b _ { 2 }} \mathbf{O}$ & 0.005 & 0.000 \\
\hline $\mathbf{N a}_{\mathbf{2}} \mathbf{O}$ & 0.178 & 0.380 \\
\hline $\mathbf{K}_{\mathbf{2}} \mathbf{O}$ & 1.176 & 0.346 \\
\hline $\mathbf{M n O}$ & 0.059 & 0.260 \\
\hline $\mathbf{T i O} \mathbf{O}_{\mathbf{2}}$ & 0.261 & 0.662 \\
\hline $\mathbf{P}_{\mathbf{2}} \mathbf{O}_{\mathbf{5}}$ & 0.064 & 0.010 \\
\hline $\mathbf{N i O}$ & 0.005 & 0.003 \\
\hline $\mathbf{Z n O}$ & 0.060 & 0.000 \\
\hline $\mathbf{S p e c i f i c ~ g r a v i t y ~}$ & 3.45 & 2.94 \\
\hline
\end{tabular}

\subsection{Methodology}

\subsubsection{Concrete mixtures and methods}

Four group of concrete specimens were formed, and the slag percentage were $0 \%$ (control), 30\%, 50\%, and $70 \%$. The mixtures proportion of the various concrete groups and their mixture designation are presented in Table 2. To ensure a homogenous mixing the concrete were mixed using a revolving pan mixer with a capacity of $60 \mathrm{~L}$. The components of each concrete mixture were batched by weight and the slag was premixed with cement, sand, and coarse aggregates before the addition of water. By continuously mixing for about 
approximately 5-6 min, homogeneity of the mix was ensured. After that, the concrete was poured into various steel and plastic molds and compacted using a vibration table to remove entrapped air[11].

Table 2: Mix proportions of concretes per cubic meter.

\begin{tabular}{lllll}
\hline \multirow{2}{*}{ Materials } & \multicolumn{4}{c}{ Mixture Designation } \\
\cline { 2 - 5 } & $\mathbf{G - 1}$ & $\mathbf{G - 2}$ & $\mathbf{G - 3}$ & $\mathbf{G - 4}$ \\
\hline Cement $(\mathbf{k g})$ & 431 & 301.7 & 215.5 & 129.3 \\
\hline GGBS $\mathbf{( k g )}$ & - & 129.3 & 215.5 & 301.7 \\
\hline Water $(\mathbf{k g})$ & 202.7 & 202.7 & 202.7 & 202.7 \\
\hline w/c & 0.47 & 0.47 & 0.47 & 0.47 \\
\hline Coarse aggregates $(\mathbf{k g})$ & 1052.6 & 1052.6 & 1052.6 & 1052.6 \\
\hline Fine aggregates $(\mathbf{k g})$ & 755.2 & 755.2 & 755.2 & 755.2 \\
\hline
\end{tabular}

Note: $w / c=$ water -to- cement ratio.

To evaluate strength characteristics of each concrete mixtures, compression test was carried out on the cubical concrete specimens by a $3000 \mathrm{KN}$ capacity testing machine according to ASTMC 39 [12]. The hightemperature heating regime was adopted from Shumuye et al. At the 7, 28, and 56 days, concrete specimens were subjected to temperature of $200{ }^{\circ} \mathrm{C}, 400{ }^{\circ} \mathrm{C}, 600{ }^{\circ} \mathrm{C}$, and $800{ }^{\circ} \mathrm{C}$ to meet the recommended fire curve specified in ISO 834 [13] using electric and gas supported furnace. The first concrete specimens' groups were subject to high-temperature exposure till it reach the target temperature. After the first phase of hightemperature exposure, the first set of concrete specimens were removed from the furnace and allowed to cooldown in the laboratory condition. To maintain the temperature constant for a given time [14], [15], the remaining concrete specimens were left at the same temperature for $2 \mathrm{~h}$.

The freeze-thaw cycles were conducted in accordance with the ASTM International C666-15 " Standard Test Method for Resistance of Concrete to Rapid Freezing and Thawing" [16]. Further, on day 28, RCPTs were performed on the saturated sample according to the Chinese standard specification GB/T 50082-2009[17] and the ASTM International test specification C-1202[18] using NT-Build 492 test method. After 5, 10, 15, 25, 40, and 50 freeze-thaw cycles, a concrete sample $50 \pm 2 \mathrm{~mm}$ in length was cut from each cylindrical concrete specimen for rapid chloride permeability test (RCPT).

A total of 3 prismatic specimens with the size of $100 \mathrm{~mm} \times 100 \mathrm{~mm} \times 515 \mathrm{~mm}$ will be tested for each 4concrete group as shown in the Fig. 4 . The shrinkage test will be carried out by non-contact method according to Chinese standard (GB/T50082-2009)[17].
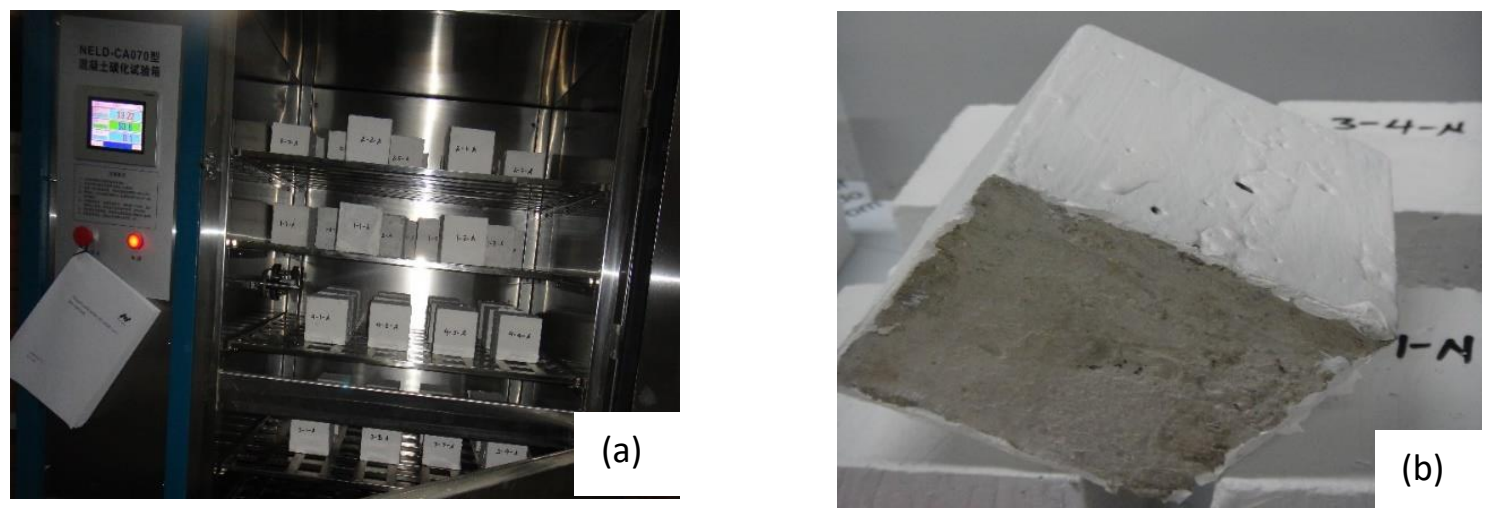

Fig. 1: (a) accelerated carbonation chamber (b) coted concrete cube

Scanning electron microscopy (SEM) and X-ray diffraction (XRD) were employed to investigate the morphology and mineralogical change of both concrete specimens exposed to high temperature and accelerated carbonation including control concrete groups. Granulated and powdered sample were extracted from various depths of concrete specimens for scanning electron microscopy (SEM) and X-ray diffraction (XRD) analysis. 
The micro-concrete specimens were placed for $24 \mathrm{hr}$. in oven at $50^{\circ} \mathrm{C}$ before microstructural analysis. To examine the morphology of concrete specimens SU3800 Scanning Electron Microscopes with the accelerating voltage of $30 \mathrm{kV}$ with working distance of $5 \pm 2 \mathrm{~mm}$ were used.

\subsubsection{Curing condition}

After $24 \mathrm{~h}$, all concrete specimens were demolded and cured in two separate curing condition. The first concrete group were held in standard curing condition with a constant temperature of $20 \pm 2^{\circ} \mathrm{C}$ and $95 \%$ relative humidity (RH) for 7, 28, and 56 days. The remaining concrete specimens were cured in high temperature curing chamber with a constant temperature of $45 \pm 2^{\circ} \mathrm{C}$ and $95 \pm 2 \%$ relative humidity (RH) for the first 7 days and then concrete specimens were reserved in standard curing condition with a constant temperature of $20 \pm 2^{\circ} \mathrm{C}$ and $95 \pm 2 \%$ relative humidity $(\mathrm{RH})$.

\section{Results and discussion}

\subsection{Mechanical properties}

\subsubsection{Cube Compressive strength}

The residual compressive strength in comparison with the control group of various cementitious materials with different slag replacement ratio is presented in Figs. 2 and 3. As shown in Fig. 2, the $7 \mathrm{~d}$ compressive strength for high temperature cured concrete specimens is higher than that of the standard cured concrete specimens.

The compressive strength increased more significantly with the longer curing period from $7 \mathrm{~d}$ to $28 \mathrm{~d}$. For the first $7 \mathrm{~d}$ of high temperature curing, all concrete group compressive strength result leads to the highest compressive strength compared to the standard-cured concrete specimens of same concrete mix. It is observed that early age compressive strength of concrete specimens curried at high temperature for concrete specimens G1, G-2, G-3, and G-4 were 106\%, 91.3\%, 96\% and 67.6\% of their target compressive strength. Whereas, based on the result obtained from the $7 \mathrm{~d}$ compressive strength of concrete specimens curried at normal curing temperature, specimens attain $82.6 \%, 75.6 \%, 74.6 \%$, and $59 \%$ of their target compressive strength. This is believed to be as a result of slow hydration and low reaction of ground granulated blast furnace slag at standard curing temperature[21]. While the increment of the $28 \mathrm{~d}$ compressive strength of concrete cured at high temperature were not as significant as that of concrete specimens curried at normal curing temperature.

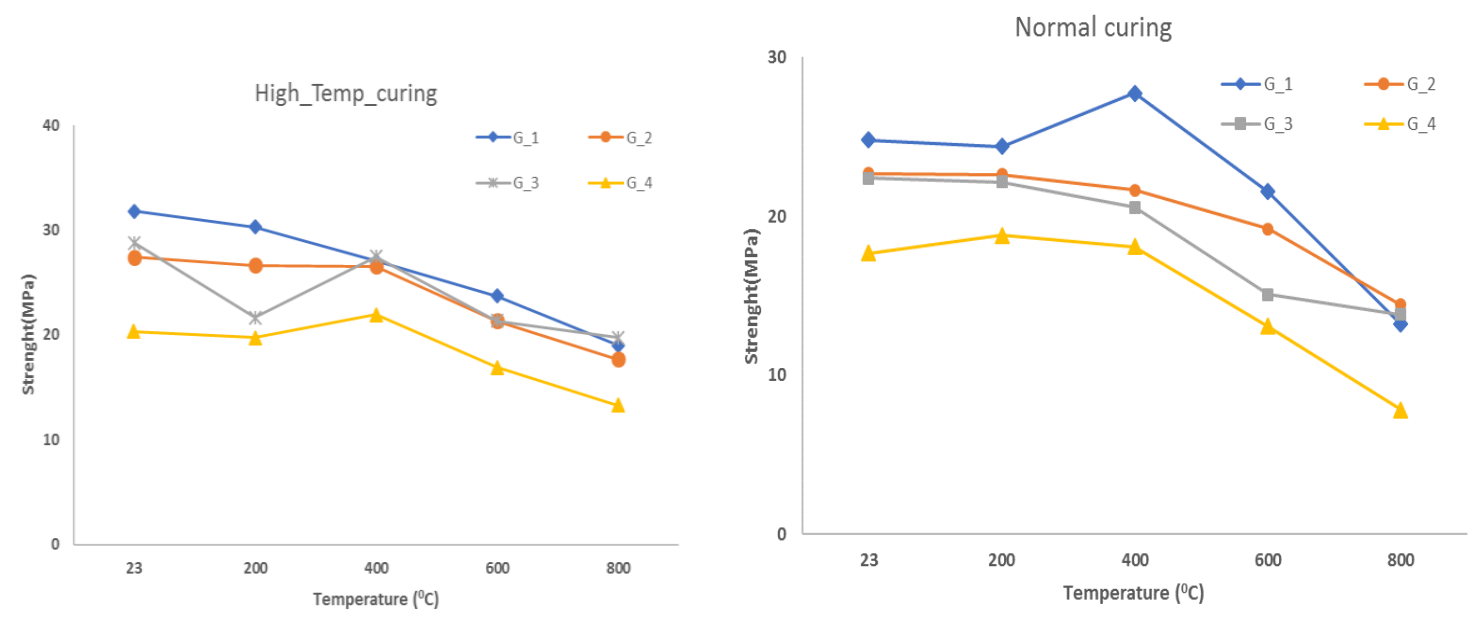

Fig. 2: Compressive strength test result after fire exposure (Exposure duration 2 hr.) (7 day).

When the concrete specimens were exposed to high temperatures, the residual compressive strength was determined after heating the concrete specimens in 200, 400, 600, and $800{ }^{\circ} \mathrm{C}$ exposure condition. In comparison with its original compressive strength results at normal curing temperature, the relative changes in residual compressive strength of each concrete specimens are plotted in Figs. 2 and 3. For all concrete group in both curing condition, the target residual compressive strength loss was observed in the slag-based samples. At a 
given high temperature exposure the residual compressive strength of the concrete specimens decreased with an increased in slag content. The residual compressive strength was fluctuating at high temperature exposure between 20 and $400{ }^{\circ} \mathrm{C}$, for both curing conditions. Same results also reported by Turker et al. (2016) [22], and Lubloy et al. (2017)[23]. All concrete specimens show a major reduction in compressive strength at 600 and $800{ }^{\circ} \mathrm{C}$ high temperature exposure condition. However, the drop in the residual compressive strength with an increasing of exposure temperature was found to be significant in case of concrete cured at high temperature compared with standard curing condition. The strength losses were $13.3 \%, 15.41 \%, 33 \%$, and $26.2 \%$ for concrete specimens of G-1, G-2, G-3, and G-4 cured at normal curing temperature respectively, when exposed to $600{ }^{\circ} \mathrm{C}$. In addition, the strength losses $25.47 \%, 22.2 \%, 26.04 \%$, and $17.24 \%$ were also recorded for concrete cured at high temperature respectively at early age. The presence of this strength change will be seen and discussed in the coming section of qualitative observations.
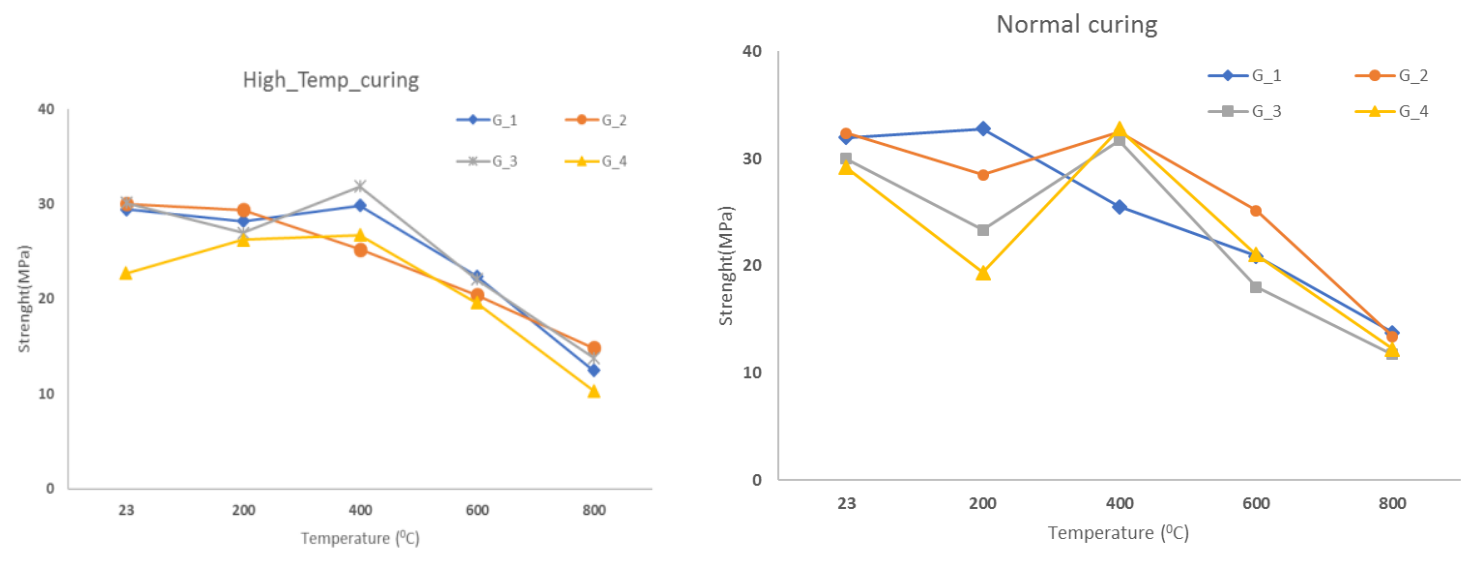

Fig. 3: Compressive strength test result after fire exposure (Exposure duration $2 \mathrm{hr}$.) (28 day).

\subsubsection{Drying Shrinkage}

The result exhibits the influence of GGBS cement on total shrinkage in concrete at early and later age. The experimental results show that, the total shrinkage of concrete with different replacement of slag cement increases gradually as ages goes by. The concrete mix group made from $30 \%$ slag cement (G2) had almost the same early age drying shrinkage as compared to concrete mix group made from 50\% slag cement (G3). The early age drying shrinkage of concrete mix group made from $70 \%$ slag cement (G4) had greater than concrete mix group made from 50\% slag cement (G3). Concrete mix group G4 had the lowest early age drying shrinkage. This early age shrinkage was typically related to the first $24 \mathrm{~h}$ hydration reaction period, high slag content reduced the early age drying shrinkage.

Additionally, the results indicated that high volume GGBS cement content in the concrete mix lessen the drying shrinkage of the concrete at later age. The drying shrinkage result for all concrete mix groups at later ages had similar trend but different magnitude. The presence of moisture in the concrete affected the drying shrinkage. It is known that the evaporation of moisture from the concrete surface to the environment had an influence on the drying shrinkage of the concrete[24], [25]. 

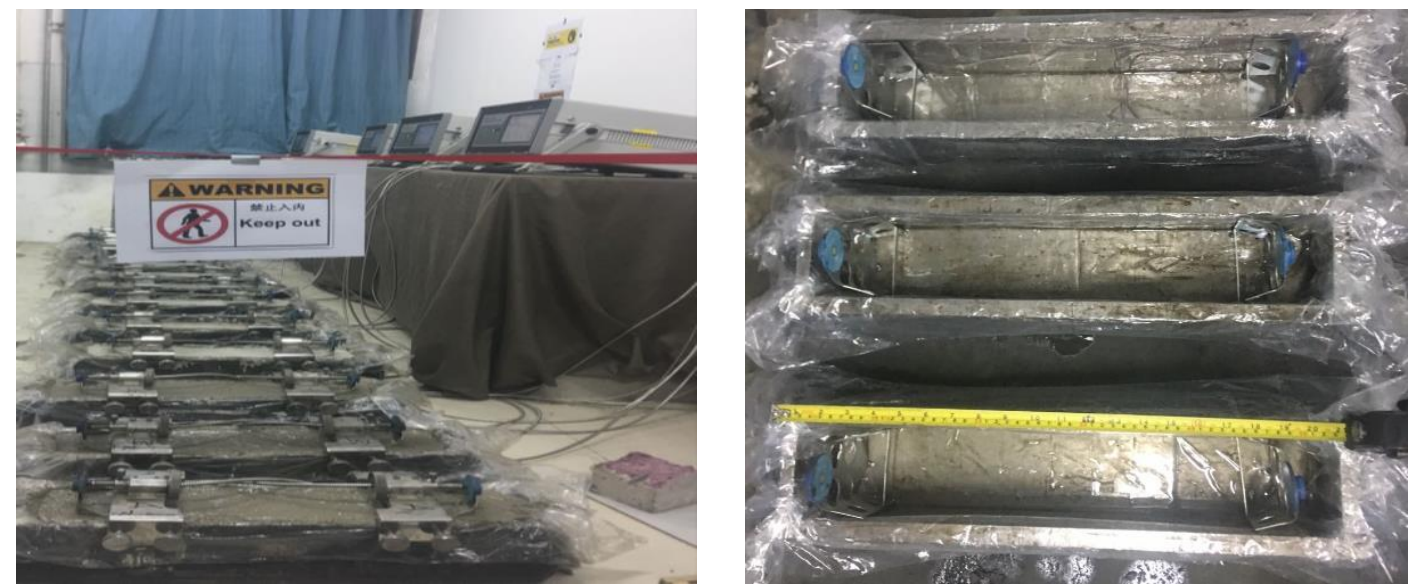

Fig. 4: None contact shrinkage deformation of concrete tester: (a) Shrinkage test laboratory setup; (b) Mold preparation.

\subsection{Physical properties}

\subsubsection{Qualitative observations}

Photographs of the specimens after exposure at $200,400,600$, and $800{ }^{\circ} \mathrm{C}$ are taken. These pictures clearly indicate the effect of slag replacement on the amount of surface cracking of the specimens after hightemperature exposure. As the ambient temperature increased, chemical and physical transformations occurred at a high speed. Beyond $100{ }^{\circ} \mathrm{C}$, physically bounded water was released. Furthermore, beyond 300 and $500{ }^{\circ} \mathrm{C}$, the silicate hydrate phase decomposed and the Portlandite dehydrated, respectively [26].

When the exposure duration and temperature increased to beyond $800{ }^{\circ} \mathrm{C}$ for $1 \mathrm{~h}$, changes in the concrete volume became evident, aggregates started to expand and undergo crystalline changes. In addition to the previously discussed strength reduction, all concrete specimens exhibited cracks, spalling, and change in color. The variation in color change was primarily dependent on the aggregate type [27]. However, the aggregates used were from the same batch. Therefore, the color change analysis was restricted to the cement paste type [28].

From visual inspection, , the variation in color of the concrete specimens is directly associated with the fire exposure. The color change of the concrete specimens due to fire exposure is irrespective of the curing temperature. All concrete specimens exposed to $200{ }^{\circ} \mathrm{C}$ for all exposure durations were gray after fire exposure. However, at $400{ }^{\circ} \mathrm{C}$, all concrete specimens exhibited some minor color variations (light gray) in compared with specimens exposed to $200{ }^{\circ} \mathrm{C}$ for a 20 -min exposure duration. However, when the exposure duration was extended to $140 \mathrm{~min}$, the color of the concrete specimen changed to (old lace $=$ light pink) for concrete groups G-3 and G-4, whereas the colors of the remaining concrete groups G-1 and G-2 remained unchanged (light gray). A similar color change to light gray in the OPC concrete specimens subjected to fire exposure was observed by Sarker, (2004) [29]. At $600{ }^{\circ} \mathrm{C}$ exposure, all concrete specimens were light gray. However, when the exposure condition was extended for $126 \mathrm{~min}$, concrete group G-1 and G-2 changed to white gray whereas concrete groups G-3 and G-4 changed to (old lace = light pink). This color change was due to the decomposition of $\mathrm{CaCO}_{3}$ into $\mathrm{CaO}$ and $\mathrm{CO}_{2}$ under fire exposure. In addition, as reported by [11], [26], [30], the presence of iron compounds in fine or coarse aggregates that decomposed to its derivatives owing to high temperature resulted in a light pink color.

Owing to the temperature variance between the surface and center of the specimens, surface cracking was prominent in many of the concrete specimens after exposure to fire. As shown in Figs. 5 and 6, the most evident surface cracking was observed in all concrete mix groups when the exposure temperature increased to $800{ }^{\circ} \mathrm{C}$. However, when the exposure temperature increased to $600{ }^{\circ} \mathrm{C}$, a major surface crack was observed for concrete groups G-1 and G-2, whereas a minor crack was observed for concrete groups G-3 and G-4 for both curing conditions. The surface crack intensity was higher for the concrete groups cured at high temperatures compared with those cured in the standard curing condition. The surface crack occurred as a result of concrete strain triggered by a temperature gradient through the cross section of the concrete [29]. Concrete specimens having a small quantity of $\mathrm{CaCO}_{3}$ in the cement paste exhibited a minor surface cracking. 


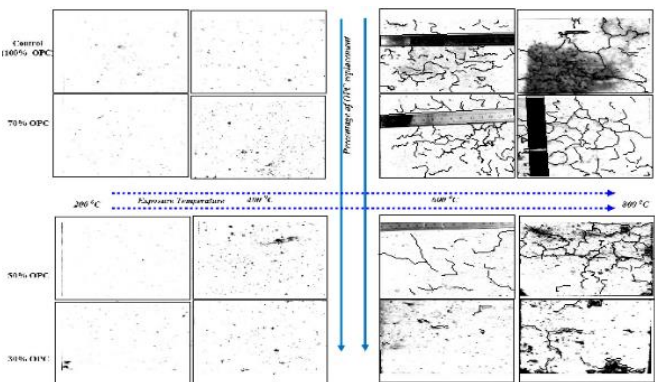

Fig. 5: Effect of percentage of slag replacement on the development of surface cracks at standard curing temperature condition.

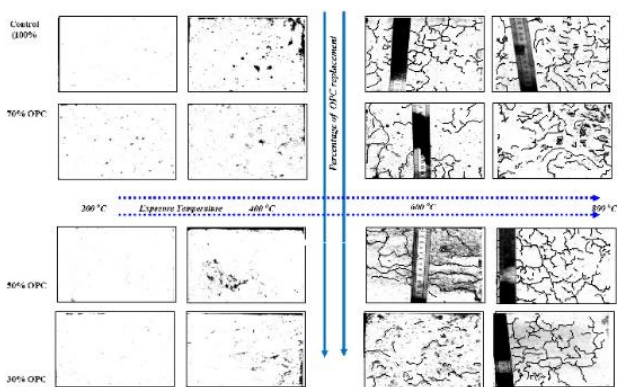

Fig. 6: Effect of percentage of slag replacement on the development of surface cracks at high-temperature curing condition.

The spalling of the concrete specimens at $800{ }^{\circ} \mathrm{C}$ is exhibited. This type of spalling was observed in all concrete specimens irrespective of the curing temperature and replacement percentage, but the size of spalling for concrete group G-1 was relatively low compared with those of the other concrete specimens. The higher resistance against disintegration and the spalling of concrete group G-1 were due to its intrinsic higher tensile strength and higher $\mathrm{CaCO}_{3}$ peak compared with those of other concrete mix groups.

\subsection{Microstructural Properties}

Concrete strength and durability in building and road construction sector are considered as the determining factor for achieving the specified service life of the structure. In order to understand the change in concrete properties, it is necessary to define and understand factors that affect the microstructure of concrete which is caused by many factors starting from preparing concrete making materials to the final service giving stage.

\subsubsection{Scanning Electron Microscopy Analysis}

In order to find to analyze the microstructural change and elemental analysis of slag and Portland cement mortars before and after exposed to accelerated carbonation and high temperature, scanning electron microscopy (SEM), X-ray diffraction (xrd) and energy dispersive spectroscopy (EDS) was induced. From the SEM images, concrete group G-1 and G-2 has more crystalline hexagonal and angular calcium aluminate and calcium hydroxide compared to concrete group G-4.

It can be observed that the hydrates which fills space are poorly crystalline in the case of concrete group G4 compared to the other concrete groups. The effect of high temperature exposure curing was noticeable for all concrete groups. Increasing curing temperature facilitate continuous reaction. As the reaction continue, the development of hydration products become denser, porosity decrease, and performance of physical and mechanical properties also enhanced. The density of hydrates products was more intensified for concrete group G-1. The effects of thermal exposure on the microstructure are presented in Fig. 7.

The exposure to $800{ }^{\circ} \mathrm{C}$ has brought distinctive changes of morphology of the slag-based binder. As the high temperature rises to $800{ }^{\circ} \mathrm{C}$, predominant amount of micro and macro cracks, disintegration and deformation of C-S-H and C-H phase were clearly spotted for all concrete groups. The micro and macro pores can be easily identified in the mortar matrix from the detail examination of SEM imaging. The decomposition of $\mathrm{CH}$ and the disappearance of crystalline phase are more aggravated with the increasing slag replacement. 


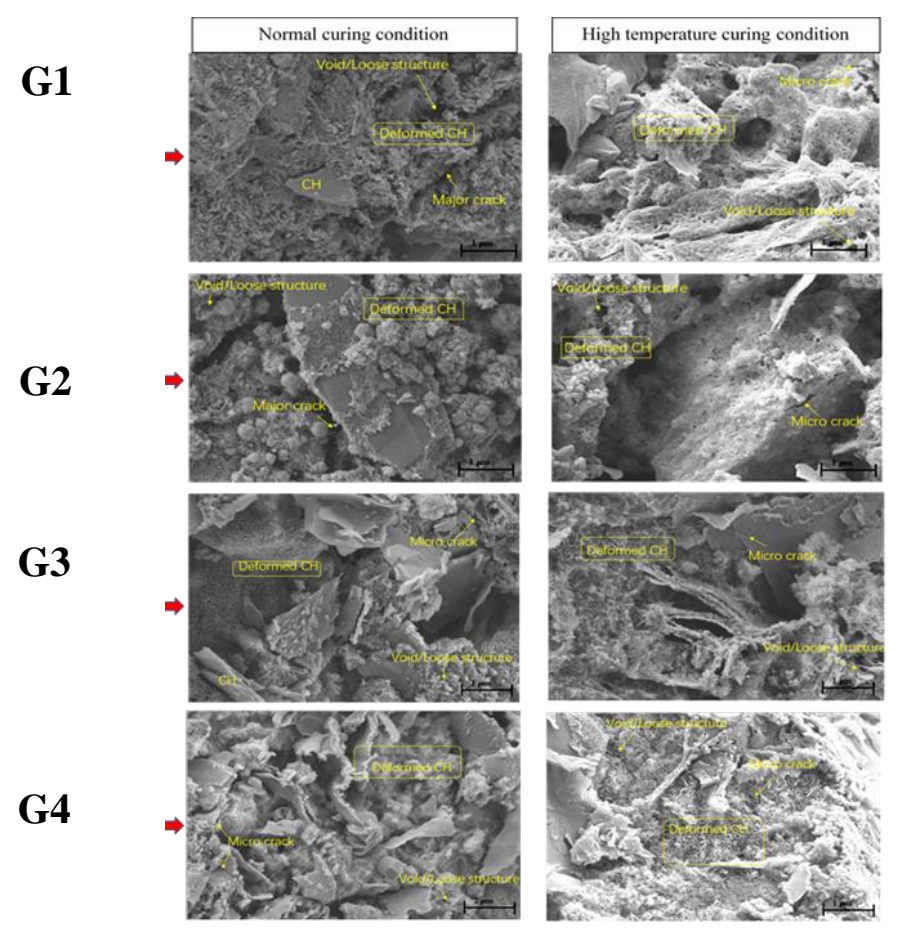

Fig. 7: SEM morphologies of blended slag cement concrete at different slag replacement level in $800{ }^{\circ} \mathrm{C}$ exposure. [28th day curing period].

The SEM and EDS analysis revealed that with increasing the slag replacement, the permeability of slag cement concrete also increased. The increased permeability for slag cement concrete indicates that the cement hydration products are affected by carbonation process. As the slag replacement increased the amount of amount of $\mathrm{CH}$ gets lower. The effect of accelerated carbonation is more intensified for concrete groups with low amount of $\mathrm{CH}$. Carbon dioxide can react with dissolved calcium hydroxide, these processes involves three main steps [31]:

(1). Dissolution of $\mathrm{CH}$

(2). Absorption of carbon dioxide and formation of carbonate ions

(3). Chemical reaction and precipitation.

It was shown that, although $\mathrm{CH}$ reacted more rapidly with time its reaction rate decreased and overtake by $\mathrm{C}-\mathrm{S}-\mathrm{H}$ phase. This facilitates a formation of relatively more dense microcrystalline calcium carbonate layer at the surface. Carbonation of C-S-H phase consists amorphous silica gel and various polymorphs of calcium carbonate and the removal of calcium ion from the phase.

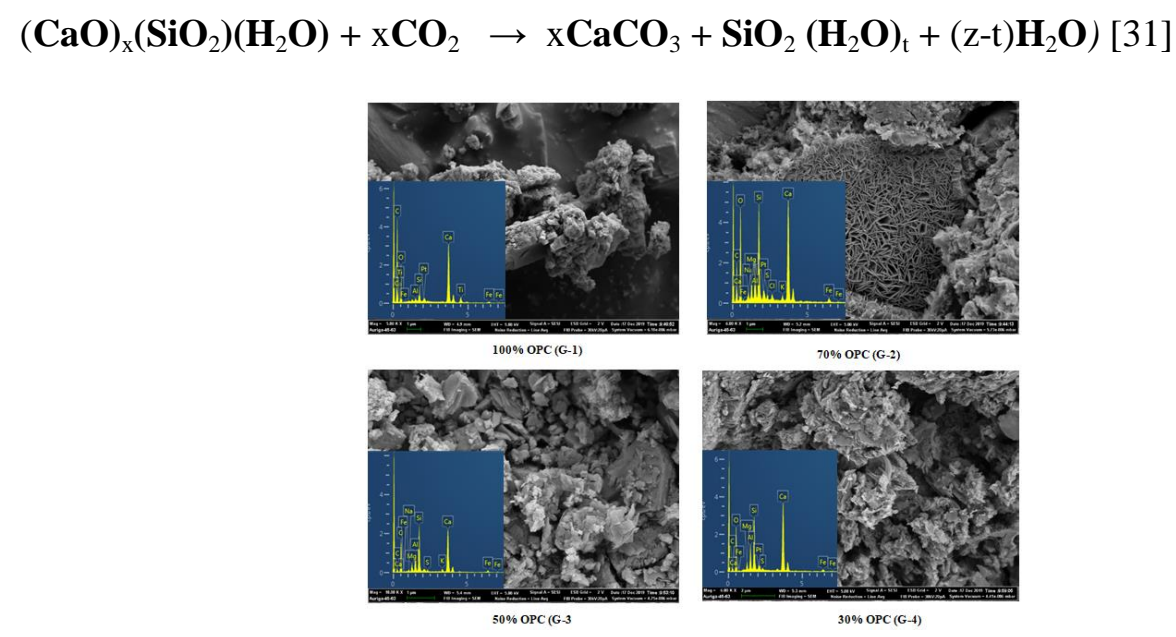

Fig. 8: SEM and EDS image of carbonated concrete specimens after accelerated carbonation exposure.

ICSECT 166- 8 
Fig. 8 depicts the mineralogical composition and microstructural phase of all concrete mixes after exposed to accelerated carbonation. The dense structure of hydrates shows in the above picture (G-1) is due to the presence of C-H, C-S-H and Portlandite. These compositions further undergo different chemical reaction. As the GGBS cement replacement increased the reaction rate of $\mathrm{Ca}(\mathrm{OH})_{2}$ with $\mathrm{CO}_{2}$ also increased, which results formation of $\mathrm{CaCO}_{3}$ and $\mathrm{H}_{2} \mathrm{O}$. Subsequently, Calcium carbonate reacts with Carbon dioxide and water due to the availability of pores for $\mathrm{CO}_{2}$ diffusion, resulting the formation of pores and Calcium bicarbonate $(\mathrm{Ca}$ $\left(\mathrm{HCO}_{3}\right)_{2}$ leading the concrete more permeable.

\subsubsection{X-Ray Diffraction}

XRD analysis was performed to study the effects of fire exposure and slag replacement level on hydration and phase changes. Fig. 9 show a section of the XRD patterns obtained from all concrete groups after fire exposure at $800^{\circ} \mathrm{C}$.

From the XRD data analysis shown in Fig. 9, it was confirmed that after fire exposure, concrete underwent mineralogical changes. One of the major chemical changes was the decomposition of $\mathrm{C}-\mathrm{S}-\mathrm{H}$ gel and the transformation of $\mathrm{Ca}(\mathrm{OH})_{2}$ into $\mathrm{CaO}$ owing to the exclusion of chemically bonded water. In addition, more peaks appeared for the alpha-beta combination of quartz aggregates after exposure to $800{ }^{\circ} \mathrm{C}$, as shown in Fig. 9. Owing to the decomposition of $\mathrm{C}-\mathrm{S}-\mathrm{H}$ gel and calcium hydroxide, the peaks of the $\mathrm{C}-\mathrm{S}-\mathrm{H}$ gel were lower than those of the unexposed concrete specimens in all concrete mixes. Other major peaks were observed, such as those of $\mathrm{SiO}_{2}$, owing to the dissociation of calcium silicate hydrate.

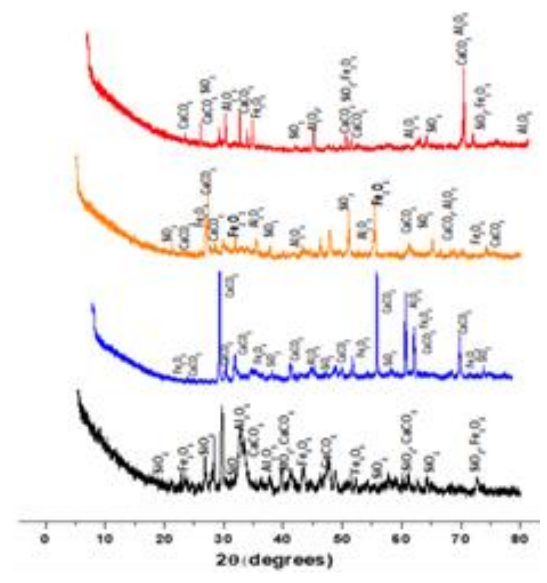

(a)

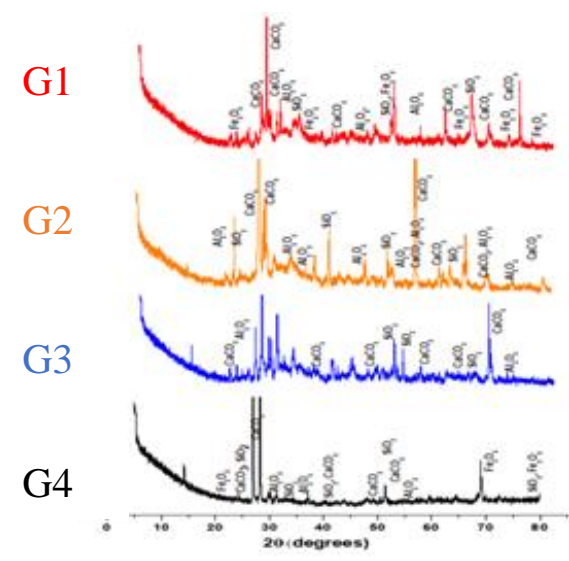

(b)

Fig.9: XRD of concrete mixes after fire $\left(800{ }^{\circ} \mathrm{C}\right)$ (a) Normal curing condition, (b) High temperature curing condition.

Based on Fig. 9, the reason for the less surface cracking of concrete groups G-3 and G-4 was the less composition of $\mathrm{CaCO}_{3}$ compared with those of concrete groups G-1 and G-2, which resulted in reduced $\mathrm{CO}_{2}$ emissions during the decomposition of $\mathrm{CaCO}_{3}$ at $800{ }^{\circ} \mathrm{C}$ exposure.

Therefore, as the slag replacement level increased, the residual amount of $\mathrm{CaCO}_{3}$ after high-temperature fire exposure decreased. Meanwhile, compared with the other cementitious compounds, the amount of $\mathrm{Al}_{2} \mathrm{O}_{3}$ increased with the slag replacement level. However, the effect of $\mathrm{Al}_{2} \mathrm{O}_{3}$ on the compressive strength of the concrete specimens were less compared to that of $\mathrm{CaO}$. The disintegration of $\mathrm{Ca}(\mathrm{OH})_{2}, \mathrm{CaCO}_{3}$, and $\mathrm{C}-\mathrm{S}-\mathrm{H}$ resulted in the formation of $\mathrm{CaO}$ and $\mathrm{CaSiO}_{2}$. Kore Sudarshan and Vyas, (2019) also [30] reported that, owing to decomposition of $\mathrm{C}-\mathrm{S}-\mathrm{H}$, the loss in mechanical properties of concrete was significant at 600 and $800{ }^{\circ} \mathrm{C}$ fire exposure.

\subsection{Durability performance}

\subsubsection{Resistance to freeze-thaw and chloride ion attack}

The results presented prove that higher percentages of slag cement resulted in lower chloride ion migration coefficients. Further, concrete groups with relatively higher percentages of slag cement exhibited superior 
resistance to chloride ion penetration following exposure to freeze-thaw cycles [32], [33]. Therefore, it can be inferred that concrete produced without the addition of slag cement would exhibit relatively weaker resistance to chloride ion penetration. According to the ASTM International standard test method 1202-05, concretes containing slag cement and fly ash possess lower chloride ion permeabilities [18]. Additionally, Lee et al. and Özbay et al. have confirmed that concrete produced entirely from slag cement exhibits comparatively higher resistance to chloride ion penetration [34], [35].

\subsubsection{Resistance to Accelerated Carbonation}

For a period of $56 \mathrm{~d}$ the carbonation depth and concrete cube compressive strength after exposure to carbon dioxide was monitored for all concrete groups by exposing to a pre-set carbon dioxide content $(15 \pm 2 \%)$. The average carbonation depth is determined by taking 8 different measure points on the exposed side only.

For the compressive strength of concrete specimens cured after exposure to carbon dioxide curing. All the concrete specimens exhibited relatively low compressive strengths as the slag replacement level increased. For example, the compressive strength of concrete specimens G-1, G-2, G-3, and G-4 ranged from 21.1 to $31.9 \mathrm{MPa}$, 17.1 to $26.0 \mathrm{MPa}, 16.5$ to $24.3 \mathrm{MPa}$ and 15.4 to $18.8 \mathrm{MPa}$ respectively. Whereas, with the curing age increasing from $3 \mathrm{~d}$ to $28 \mathrm{~d}$ under carbon dioxide curing, the compressive strength increased regardless of the slag replacement, which is due to the production of additional hydration products and the reaction of the $\mathrm{Mg}$ - and $\mathrm{Ca}$ - rich minerals in the cementitious materials, which produced various strength enhancing carbonated hydration products as confirmed many other researcher[36]. For the concrete made with $70 \%$ slag cement and $30 \%$ cement (G-4) after only $3 \mathrm{~d}$ of carbon dioxide curing, compared with concrete made with $100 \%$ OPC (G1 ), the compressive strengths were decreased by $27 \%$, while the other concrete group made by $50 \%$ and $30 \%$ slag cement were decreased by approximately $21.8-18.9 \%$.

When supplementary cementitious or pozzolanic materials are used as a partial replacement to Portland cement, $\mathrm{CH}$ is consumed during the pozzolanic reaction, which produces $\mathrm{C}-\mathrm{S}-\mathrm{H}$ gel. For this reason, less portlandite is available for carbonation, which affect the mechanical and microstructural properties of concrete. Concrete group G-1 attains the highest compressive strength compared to the other concrete group, due to having higher amount of minerals that could be carbonated[36]. The rate of carbonation of GGBS cement concrete is significantly higher than that of OPC concrete. With the increasing the amount of GGBS replacement, the carbonation rate of the concrete paste increases, and this carbonation process is highly influenced by the amount of $\mathrm{CH}$ content[31]. The results comparison of different concrete mixture exposed to carbon dioxide obtained by different researchers are always difficult to interpreted and relate each other, due to the difference in slag compositions, slag replacement ration and initial curing condition. However, some previously published related research works results shows that increasing the percentage of slag replacement facilitate high rate of carbonation depth.

\section{Conclusions}

Concrete produced with slag cement and curried in high temperature and standard conditions were exposed to varying number of high temperatures, freeze-thaw cycles, accelerated carbonation and chloride ion attack. Concrete specimens made from OPC (PO 42.5 R) were also exposed to the same conditions. The compressive strength, residual compressive strength, migration coefficients, chloride ion penetration depth, carbonation depth, microstructural properties (via SEM), and mineralogical change (via XRD and EDS) were investigated in addition to the porosities of the concrete specimens. From the experimental data and observation, the following conclusions can be drawn:

1. It appeared that $600{ }^{\circ} \mathrm{C}$ is considered as a critical temperature corresponding to a substantial change of the mineralogical change and microstructural alteration as well as significant reduction of mechanical strength from the tested temperature.

2. The surface crack intensity was higher for concrete groups cured at high temperatures compared with concrete groups cured in the standard curing condition. More surface cracks did not imply a low compressive strength.

3. Repeated exposure to freeze-thaw cycles increased the pore volumes of samples that contained a percentage of slag replacement, and this trend was enhanced in the control group that contained $0 \%$ slag. 
However, even after exposure to freeze-thaw cycles, concrete samples containing slag cement exhibited more compacted pore structures than that of the OPC concrete. These changes in the internal pore structures were evident in the demonstrated resistances to chloride ion penetration.

4. Chloride ion penetration depths decreased as the percentage of slag replacement increased but increased in all specimens with exposure to increasing numbers of freeze-thaw cycles.

5. Increasing GGBS cement content in concrete mixes, were also increased the rate of carbonation and carbonation depth.

\section{Acknowledgement}

Experimental work described in this paper was financially supported by Program for Innovative Research Team of Education Ministry of China (IRT_16R67), Thousand Talents Plan in Henan Province (ZYQR201912029), and the National Natural Science Foundation of China (51908512).

\section{Conflict of interest}

The authors declare that they have no conflict of interest.

\section{Reference}

[1] J. Ren, H. Chen, T. Sun, H. Song, and M. Wang, "Flexural Behaviour of Combined FA/GGBFS Geopolymer Concrete Beams after Exposure to Elevated Temperatures," Advances in Materials Science and Engineering, vol. 2017, pp. 1-9, 2017, doi: 10.1155/2017/6854043.

[2] P. Saranya, P. Nagarajan, and A. P. Shashikala, "Behaviour of GGBS-dolomite geopolymer concrete short column under axial loading," Journal of Building Engineering, vol. 30, p. 101232, Jul. 2020, doi: 10.1016/j.jobe.2020.101232.

[3] "EE23-Reduce CO2 Emissions Due to Concrete," URBAN GREEN, p. 3.

[4] C09 Committee, "Specification for Blended Supplementary Cementitious Materials," ASTM International. doi: 10.1520/C1697-18.

[5] V. B. R. Suda and P. Srinivasa Rao, "Experimental investigation on optimum usage of Micro silica and GGBS for the strength characteristics of concrete," Materials Today: Proceedings, p. S2214785319343846, Jan. 2020, doi: 10.1016/j.matpr.2019.12.354.

[6] J. Liu and R. Guo, "The microstructures of hardened composite binders containing steel slag and GGBS at 10 years," Construction and Building Materials, vol. 225, pp. 1152-1159, Nov. 2019, doi: 10.1016/j.conbuildmat.2019.08.026.

[7] V. G. Papadakis, M. P. Efstathiou, and C. A. Apostolopoulos, "Computer-aided approach of parameters influencing concrete service life and field validation," Computers and Concrete, vol. 4, no. 1, pp. 1-18, Feb. 2007, doi: 10.12989/CAC.2007.4.1.001.

[8] Luo, Su, Xu, Ou, and Peng, "Axial Compression Performance of Post-Fire Concrete Columns Strengthened Using Thin-Walled Steel Tubes," Sustainability, vol. 11, no. 18, p. 4971, Sep. 2019, doi: 10.3390/su11184971.

[9] ASTM Committee C09, "Standard Specification for Ground Granulated Blast-Furnace Slag for Use in Concrete and Mortars." ASTM International, 2004.

[10] China Building Materials Science Research Institute, "NATIONAL STANDARD OF THE PEOPLE'S REPUBLIC OF CHINA," People's Republic of China \& Standardization Administration of China, GB 175-2007, Nov. 2007.

[11] E. D. Shumuye, J. Zhao, and Z. Wang, "Effect of fire exposure on physico-mechanical and microstructural properties of concrete containing high volume slag cement," Construction and Building Materials, vol. 213, pp. 447-458, Jul. 2019, doi: 10.1016/j.conbuildmat.2019.04.079.

[12] ASTM International, "Standard Test Method for Compressive Strength of Cylindrical Concrete Specimens," United States, C 39/C 39M - 01, 2001.

[13] ISO 834-1-1999, "Fire resistance Test-Element of Building Construction." 1999.

[14] H. Yang, H. Zhao, and F. Liu, "Residual cube strength of coarse RCA concrete after exposure to elevated temperatures," Fire and Materials, vol. 42, no. 4, pp. 424-435, Jun. 2018, doi: 10.1002/fam.2508. 
[15] H. Zhao, Y. Wang, and F. Liu, "Stress-strain relationship of coarse RCA concrete exposed to elevated temperatures," Magazine of Concrete Research, vol. 69, no. 13, pp. 649-664, Jul. 2017, doi: 10.1680/jmacr.16.00333.

[16] ASTM C09 Committee, "Test Method for Resistance of Concrete to Rapid Freezing and Thawing," ASTM International, 2004. doi: 10.1520/C0666_C0666M-03R08.

[17] GB/T 50082, "The national standard for long-term performance and durability test methods of ordinary concrete." China construction industry press, 2009, [Online]. Available: www.china-building.com.cn.

[18] ASTM C1202 - 10, "Standard Test Method for Electrical Indication of Concrete's Ability to Resist Chloride Ion Penetration." ASTM International, Mar. 2010.

[19] J. Wang et al., "Accelerated carbonation of hardened cement pastes: Influence of porosity," Construction and Building Materials, vol. 225, pp. 159-169, Nov. 2019, doi: 10.1016/j.conbuildmat.2019.07.088.

[20] Mhmmat. HYDROCARBONt, "CPC-18 Measurement of hardened concrete carbonation depth,” p. 3.

[21] Z. Pan, "Compressive strength and microstructure of alkali-activated fly ash/slag binders at high temperature," p. 32.

[22] H. T. Türker, M. Balçikanli, İ. H. Durmuş, E. Özbay, and M. Erdemir, "Microstructural alteration of alkali activated slag mortars depend on exposed high temperature level," Construction and Building Materials, vol. 104, pp. 169-180, Feb. 2016, doi: 10.1016/j.conbuildmat.2015.12.070.

[23] É. Lublóy, K. Kopecskó, G. L. Balázs, Á. Restás, and I. M. Szilágyi, "Improved fire resistance by using Portland-pozzolana or Portland-fly ash cements," Journal of Thermal Analysis and Calorimetry, vol. 129, no. 2, pp. 925-936, Aug. 2017, doi: 10.1007/s10973-017-6245-0.

[24] S. Dueramae, W. Tangchirapat, P. Chindaprasirt, C. Jaturapitakkul, and P. Sukontasukkul, "Autogenous and drying shrinkages of mortars and pore structure of pastes made with activated binder of calcium carbide residue and fly ash," Construction and Building Materials, vol. 230, p. 116962, Jan. 2020, doi: 10.1016/j.conbuildmat.2019.116962.

[25] S. Saluja, K. Kaur, S. Goyal, and B. Bhattacharjee, "Assessing the effect of GGBS content and aggregate characteristics on drying shrinkage of roller compacted concrete," Construction and Building Materials, vol. 201, pp. 72-80, Mar. 2019, doi: 10.1016/j.conbuildmat.2018.12.179.

[26] Joakim Albrektsson, Mathias Fla and Jan Erik Lindqvist and Robert J, "Assessment of concrete structures after fire," SP Sveriges Tekniska Forskningsinstitut, Sweden, Brandforsk project number: 301-091, 2011.

[27] A. Lau and M. Anson, "Effect of high temperatures on high performance steel fibre reinforced concrete," Cement and Concrete Research, vol. 36, no. 9, pp. 1698-1707, Sep. 2006, doi: 10.1016/j.cemconres.2006.03.024.

[28] E. Annerel and L. Taerwe, "Methods to quantify the colour development of concrete exposed to fire," Construction and Building Materials, vol. 25, no. 10, pp. 3989-3997, Oct. 2011, doi: 10.1016/j.conbuildmat.2011.04.033.

[29] P. K. Sarker, "Effect of fire exposure on cracking, spalling and residual strength of fly ash geopolymer concrete," p. 36, 2004.

[30] D. Kore Sudarshan and A. K. Vyas, "Impact of fire on mechanical properties of concrete containing marble waste," Journal of King Saud University - Engineering Sciences, vol. 31, no. 1, pp. 42-51, Jan. 2019, doi: 10.1016/j.jksues.2017.03.007.

[31] B. Šavija and M. Luković, "Carbonation of cement paste: Understanding, challenges, and opportunities," Construction and Building Materials, vol. 117, pp. 285-301, Aug. 2016, doi: 10.1016/j.conbuildmat.2016.04.138.

[32] Paweena Jariyathitipong, "Improving The Durability Of Concrete Through The Use Of Ground Granulated Blast Furnace Slag And Blast Furnace Slag Sand," Okayama University, Japan, 2014.

[33] I. Yuksel, "Blast-furnace slag," in Waste and Supplementary Cementitious Materials in Concrete, Elsevier, 2018, pp. 361-415.

[34] B. Lee, G. Kim, J. Nam, B. Cho, Y. Hama, and R. Kim, "Compressive strength, resistance to chloride-ion penetration and freezing/thawing of slag-replaced concrete and cementless slag concrete containing desulfurization slag activator," Construction and Building Materials, vol. 128, pp. 341-348, Dec. 2016, doi: 10.1016/j.conbuildmat.2016.10.075. 
[35] E. Özbay, O. Karahan, M. Lachemi, K. M. A. Hossain, and C. D. Atis, "Dual effectiveness of freezingthawing and sulfate attack on high-volume slag-incorporated ECC," Composites Part B: Engineering, vol. 45, no. 1, pp. 1384-1390, Feb. 2013, doi: 10.1016/j.compositesb.2012.07.038.

[36] L. Mo, F. Zhang, M. Deng, F. Jin, A. Al-Tabbaa, and A. Wang, “Accelerated carbonation and performance of concrete made with steel slag as binding materials and aggregates," Cement and Concrete Composites, vol. 83, pp. 138-145, Oct. 2017, doi: 10.1016/j.cemconcomp.2017.07.018.

[37] M. Á. Sanjuán, E. Estévez, C. Argiz, and D. del Barrio, "Effect of curing time on granulated blast-furnace slag cement mortars carbonation," Cement and Concrete Composites, vol. 90, pp. 257-265, Jul. 2018, doi: 10.1016/j.cemconcomp.2018.04.006. 